\title{
Growth and nutrient intake among very-low-birth-weight infants fed fortified human milk during hospitalisation
}

\author{
Christine Henriksen ${ }^{1}$, Ane C. Westerberg ${ }^{1}$, Arild Rønnestad ${ }^{2}$, Britt Nakstad $^{3}$, Marit B. Veierød ${ }^{1,4}$, \\ Christian A. Drevon ${ }^{1}$ and Per O. Iversen ${ }^{1,5}$ \\ ${ }^{1}$ Department of Nutrition, Faculty of Medicine, Institute of Basic Medical Sciences, University of Oslo, Oslo, Norway \\ ${ }^{2}$ Department of Pediatrics, Oslo University Hospital Rikshospitalet, Oslo, Norway \\ ${ }^{3}$ Department of Pediatrics, Akershus University Hospital and Akershus Faculty Division, Akershus, Norway \\ ${ }^{4}$ Biostatistics, Faculty of Medicine, Institute of Basic Medical Sciences, University of Oslo, Oslo, Norway \\ ${ }^{5}$ Department of Haematology, Oslo University Hospital, Ullevaal, Oslo, Norway
}

(Received 5 August 2008 - Revised 30 March 2009 - Accepted 1 April 2009 - First published online 18 May 2009)

Postnatal growth failure in preterm infants is due to interactions between genetic and environmental factors, which are not fully understood. We assessed dietary supply of nutrients in very-low-birth-weight (VLBW, $<1500 \mathrm{~g}$ ) infants fed fortified human milk, and examined the association between nutrient intake, medical factors and growth during hospitalisation lasting on average $70 \mathrm{~d}$. We studied 127 VLBW infants during the early neonatal period. Data were obtained from medical records on nutrient intake, growth and growth-related factors. Extra-uterine growth restriction was defined as body weight $<10$ th percentile of the predicted value at discharge. Using logistic regression, we evaluated nutrient intake and other relevant factors associated with extra-uterine growth restriction in the subgroup of VLBW infants with adequate weight for gestational age at birth. The proportion of growth restriction was $33 \%$ at birth and increased to $58 \%$ at discharge from hospital. Recommended values for energy intake $(>500 \mathrm{~kJ} / \mathrm{kg}$ per d) and intra-uterine growth rate $(15 \mathrm{~g} / \mathrm{kg}$ per d) were not met, neither in the period from birth to 28 weeks post-conceptional age (PCA), nor from 37 weeks PCA to discharge. Factors negatively associated with growth restriction were energy intake $\left(P_{\text {trend }}=0 \cdot 002\right)$, non-Caucasian ethnicity $(P=0.04)$ and weight/predicted birth weight at birth $\left(P_{\text {trend }}=0.004\right)$. Extra-uterine growth restriction is common in VLBW infants fed primarily fortified human milk. Currently recommended energy and nutrient intake for growing preterm infants was not achieved. Reduced energy supply and non-Caucasian ethnicity were risk factors for growth restriction at discharge from hospital.

Very low birth weight: Preterm infants: Growth: Energy: Diet

Adequate nutrition during infancy and early childhood is important for normal human development. The period from mid-pregnancy to the age of 2 years is characterised by rapid growth and development of the central nervous system. The immediate consequences of inadequate perinatal nutritional supply include increased morbidity, suboptimal growth and delayed mental and motor development ${ }^{(1)}$. In the long term, early nutritional deficits are linked to impairments of intellectual performance, reduced work capacity and elevated risk for CHD and the metabolic syndrome ${ }^{(1)}$.

Preterm infants have high nutrient requirements because they have missed the last trimester placental transfer of nutrients, and have therefore very small energy and nutrient reserves. Feeding problems are frequent, and most infants need parenteral feeding. Due to improved survival rate of very-low birth weight (VLBW; birth weight $<1500 \mathrm{~g}$ ) infants, the nutritional challenges of these infants have received increasing attention ${ }^{(2)}$.

Human milk is the preferred source of enteral feeding. In the Nordic countries, this milk is unpasteurised, and comes either from the mother or from a human milk donor ${ }^{(3)}$. Human milk feeding has several advantages compared with formula feeding. In addition to nutrients, human milk contains components with a positive effect on tolerance of enteral feeding. Moreover, feeding with human milk is associated with fewer infections, reduced frequency of necrotising enterocolitis, shorter stay in hospital and better psychomotor development as compared with other feeding regimens ${ }^{(4-6)}$. However, human milk does not contain enough energy and essential nutrients to meet the very high requirements in VLBW infants, and preterm infants fed human milk apparently have a slower growth rate than formula-fed infants ${ }^{(7)}$. Fortification of human milk with energy, protein and minerals is associated with better weight gain, and improved length and head growth ${ }^{(8)}$. However, the optimal supply of energy and specific nutrients to this vulnerable group has not been established. Hence future research should be directed toward evaluating both short- and long-term outcomes in search of the optimal composition of fortifiers to preterm infants ${ }^{(8)}$. 
Growth restriction in preterm infants indicates that the nutrient requirements have not been adequately met, and there is a potential for improving the supply of macro- as well as micronutrients. On the other hand, too much energy may increase fat accumulation instead of lean body mass and thus potentially increase the risk of CHD later in life ${ }^{(9)}$. Given this fine balance where too low as well as too high supply might be harmful, it is crucial to determine the optimal nutrient intake for these infants. The aim of the nutrition therapy of VLBW infants is to approximate intra-uterine growth and development ${ }^{(10)}$. Studies from both USA and Western Europe have shown that this is seldom achieved and that many preterm infants are small for gestational age when they are discharged from hospital ${ }^{(11)}$. It is not known whether this is the case also for infants receiving fortified human milk.

Thus, the aim of the present study was to assess nutrient intake and growth in VLBW infants fed primarily fortified human milk during hospitalisation, and to examine the association between nutrient intake and growth development during hospitalisation. Such knowledge is required before further improvement of feeding protocols can be made.

\section{Methods}

\section{Subjects}

Out of 217 VLBW infants consecutively born between December 2003 and October 2005 at four different hospitals (Rikshospitalet University Hospital, Akershus University Hospital, Buskerud Hospital and Vestfold Hospital) in Norway, 136 infants were eligible for the study. Exclusion criteria were major congenital abnormalities, cerebral haemorrhage (grade 3 or 4 ) as determined by ultrasound examination, death or parental denial of enrolment. Fifty-nine infants did not meet the inclusion criteria, and twenty-two parents refused to participate. Of the 136 infants included in the study, two died, three were excluded because of complications with major influence on their food intake and one infant was diagnosed with Down's syndrome. Three medical records were not available at the time of data collection, and these infants were also excluded. Thus, 127 infants are included in our analyses. The study was a part of an intervention study concerning the effect of long-chain PUFA on cognitive development in childhood, where the infants received a supplement of either a 50:50 mixture of $n-3$ and $n-6$ fatty acid or an equal amount of vegetable oil ${ }^{(12)}$. The present study was conducted according to the guidelines laid down in the Declaration of Helsinki and all procedures involving human patients were approved by the Regional Ethics Committee in Norway. Written informed consent was obtained from the parents.

\section{Growth}

Data about weight gain and head circumference were taken from the medical records. All infants were routinely weighed by the nursing staff every day or every second day. The scales had an accuracy of at least $\pm 5 \mathrm{~g}$. Length was measured at birth and weekly until discharge at two of the hospitals. All nurses were trained on standard measurement techniques. Growth restriction at birth and discharge was defined as weight $<$ the 10th percentile for post-conceptional age
(PCA) according to updated Norwegian growth charts for fetal growth ${ }^{(13)}$. Adequate weight for age at birth and discharge was defined as weight $>10$ th percentile for PCA. PCA was based on routine ultrasound examination, conducted at approximately 18 weeks of gestation.

\section{Nutrient intake}

Dietary intake among VLBW infants during the neonatal period was estimated from daily records of the actual intake of parenteral nutrition, human milk and formulas during the hospital stay. Nutrient intakes from supplements were also included. The daily nutrient intake of each infant was calculated using a computer program and food database (developed at the Department of Nutrition, University of Oslo, Norway). Data on commercially available products for preterm infants were obtained from the manufacturers and added to the database. Data on nutrient content in human milk were obtained from Saarela et al. ${ }^{(14)}$, using different values for preterm milk $(294 \mathrm{~kJ}, 3.8 \mathrm{~g}$ fat and $1.5 \mathrm{~g}$ protein per $100 \mathrm{ml})$ and donor milk $(261 \mathrm{~kJ}, 3 \cdot 2 \mathrm{~g}$ fat and $1.1 \mathrm{~g}$ protein per $100 \mathrm{ml})$. Energy intake is expressed in $\mathrm{kJ}(1 \mathrm{kcal}=4 \cdot 18 \mathrm{~kJ})$.

All infants received fortified human milk, either from their own mother or from a donor. Minimal enteral feeding with human milk was started as soon as possible, on the first or second day of life. The amount of parenteral feeding was reduced as the intake of human milk gradually increased. When the infants achieved an enteral intake of about $120 \mathrm{ml} / \mathrm{kg}$, the human milk was fortified with energy $(30 \mathrm{~kJ} /$ $100 \mathrm{ml})$, proteins $(0.8 \mathrm{~g} / 100 \mathrm{ml})$ and minerals (Presemp; Semper AB, Stockholm, Sweden; or Enfamil Human Milk Fortifier; Mead Johnson, Evansville, IN, USA). The two fortifiers are quite similar in energy and protein content, but the Presemp fortifier does not include vitamins. Thus, infants receiving Presemp were given oral vitamin supplement (Multibionta; Trophen Merck, Darmstadt, Germany) containing $12.5 \mu \mathrm{g}$ vitamin $\mathrm{D}, 750 \mu \mathrm{g}$ vitamin A (retinyl palmitate) and $2 \mathrm{mg}$ vitamin $\mathrm{E}$ ( $\alpha$-tocopherol). Infants in need of parenteral nutrition additionally received $1-4 \mathrm{ml} / \mathrm{kg}$ per $\mathrm{d}$ of a mixture containing fat-soluble vitamins (Vitalipid Infant; Fresenius Kabi, Oslo, Norway) and water-soluble vitamins (Soluvit; Fresenius Kabi). Infants treated with antibiotics routinely received $0.5 \mathrm{mg}$ vitamin $\mathrm{K}_{1}$ every third day. Most VLBW infants received one additional daily dose of vitamin $\mathrm{E}$ (up to $15 \mathrm{mg}$ ) from birth to 32 weeks PCA. At discharge, $76 \%$ of the infants received only human milk. The remaining infants received different combinations of formulas and human milk. Food intake of breast-fed infants was calculated by weighing the infants before and after each meal. Infants receiving human donor milk during hospitalisation changed to term formula during the last days before discharge, at the mean age of $70 \mathrm{~d}$.

\section{Statistics}

Data are presented as mean values and standard deviations and groups are compared by a $t$ test when normal distribution was met. Non-normally distributed data are presented as medians with interquartile ranges ( 25 and 75 percentiles) and groups are compared by the Mann-Whitney test. Categorical data are presented as percentages or actual numbers, and groups are compared by the $\chi^{2}$ test. 
The infants were categorised into two groups according to growth status at discharge: growth-restricted infants (n 74) and infants with adequate weight ( $n$ 53). Observations were further categorised into four groups based on PCA of the infants: $<28$ weeks, 29-32 weeks, 33-36 weeks and >37 weeks age.

To study the energy and nutrient intake in relation to growth restriction at discharge, we used a linear mixed model for repeated measures (mixed model procedure in SPSS; SPSS Inc., Chicago, IL, USA). The covariance structure was a firstorder autoregressive structure with heterogeneous variances.

In the subgroup of infants who were adequate weight for age at birth, the association between nutrient intake and growth restriction at discharge was examined by logistic regression analyses. Results are presented as OR with $95 \%$ CI. Nutrient intake was categorised into tertiles. Test for trend across tertiles of variables was performed by treating the tertiles as continuous variables in the logistic regression analysis. Dietary intakes of protein, fat and $\mathrm{Ca}$ were highly correlated to energy intake (Pearson's $r$ : $0.65 \leq r \leq 0.95$ ) and these nutrients were energy adjusted by the residual $\operatorname{method}^{(15)}$. Total energy intake was included in the multiple regression models for nutrients.

In the final model for nutrient intake, adjustments were made for weight ratio at birth (actual weight/50th percentile weight for gestational age at birth) and ethnicity. Additional adjustments for gestational age, respiratory support, length of hospitalisation and sex did not change the results. All statistical analyses were performed with SPSS (version 14.0; SPSS Inc.) and a $5 \%$ level of significance was used.

Because our present study was part of a larger study, the power calculations were performed on the basis of the Ages and Stages Questionnaire as the main endpoint. We estimated that sixty-three participants in each group would be satisfactory to have $80 \%$ power for detecting a difference at the $5 \%$ significance level of 21 points (corresponding to 0.5 $\mathrm{SD}$ ), with a mean value of 260 points $^{(12)}$. With the same assumptions, we were able to detect a difference of $251 \mathrm{~kJ}$ $(60 \mathrm{kcal})$ per $\mathrm{d}$ (corresponding to $0.5 \mathrm{SD}$ ) between groups in the present study.

\section{Results}

\section{Study subject characteristics}

At birth, $33 \%$ of the infants were small for gestational age (birth weight $<10$ th percentile weight for gestational age), and the proportion of growth-restricted individuals increased to $58 \%$ at discharge, on average $70 \mathrm{~d}$ after birth. Growth-restricted infants at discharge were characterised by a significantly higher proportion of small-for-gestational-age infants at birth (63v. 11\%), more non-Caucasians (26v. $11 \%)$, shorter duration of respiratory support (11 v. 33d) and higher gestational age at birth (29.6 v. 27.8 weeks), as compared with infants with adequate weight at discharge (Table 1). There was an indication of a shorter hospital stay among the growth-restricted compared with nongrowth-restricted infants (66 v. $77 \mathrm{~d} ; P=0.06)$. There was no significant difference in birth weight or any maternal characteristics between growth-restricted infants and infants with adequate weight at discharge.

\section{Diet}

All but four infants in the growth-restricted group and all but one among those with adequate growth received parenteral nutrition. The volume of parenteral nutrition, however, was small (mean $9.45 \mathrm{ml} / \mathrm{d}$ ) according to the routines at the departments, and the mean intake did not differ between groups. Full enteral feeding (defined as $150 \mathrm{ml} / \mathrm{kg}$ per d) was achieved after a median of $7 \mathrm{~d}$. Two of the infants were treated for necrotising enterocolitis (both in the growth-restricted group). During the hospitalisation, $76 \%$ of the infants received human milk from their own mother and $24 \%$ from a combination of mother's and donor milk.

\section{Energy and nutrient intake}

Growth-restricted infants at discharge were characterised by significantly lower intakes of energy, protein and fat, and there was an indication of lower intakes of vitamin A, vitamin $\mathrm{D}$ and $\mathrm{Ca}$ as compared with infants with adequate weight for age at discharge. The overall energy intake did not differ between groups when expressed as $\mathrm{kJ} / \mathrm{kg}$ per $\mathrm{d}$ (Table 1).

The growth-restricted infants had a lower energy intake during the study period compared with infants with adequate growth and there was a significant interaction between PCA and growth status at discharge $\left(P_{\text {interaction }}<0.001\right)$ (Fig. 1(a)). The energy intake per $\mathrm{kg}$ body weight was lowest in the first month of life, where only $16 \%$ of the growth-restricted and $23 \%$ of infants with adequate weight at discharge reached the recommended intake $(500 \mathrm{~kJ} / \mathrm{kg}$ per d). In the second period (29-33 weeks PCA), $48 \%$ of the growth-restricted and $72 \%$ of infants with adequate weight at discharge reached the recommended intake, and the difference between groups was significant $(P<0 \cdot 001)$. After 37 weeks, the energy intake per $\mathrm{kg}$ body weight decreased in both groups. A similar pattern was observed for protein intake (data not shown), as energy and protein were highly correlated in this group.

Growth-restricted boys had a slightly higher energy intake compared with the girls $(757 v .705 \mathrm{~kJ} / \mathrm{d})$, but there were no apparent sex differences in intake of energy and protein per $\mathrm{kg}$ body weight.

\section{Growth}

The weight gain compared with expected intra-uterine growth rate $^{(13)}$ is shown in Fig. 1(b). Infants with adequate growth had higher growth rate compared with growth-restricted infants between 29 and 32 weeks of age $(P<0.001)$ (Table 1$)$. The growth rate was lower than the estimated intra-uterine growth rate $(15 \mathrm{~g} / \mathrm{kg}$ per d) for both groups of infants in the beginning $(<28$ weeks PCA) and at the end $(>37$ weeks PCA) of the study period. The time period of the most pronounced growth restriction was different in infants with extremely low birth weight (ELBW; birth weight $<1000 \mathrm{~g}$ ) as compared with infants with birth weight 1000-1500 g. ELBW infants had lower weight gain in the beginning of the study period ( $<28$ weeks PCA: $8.6 \mathrm{~g} / \mathrm{kg}$ per d) than later (after 28 weeks PCA: $17.6 \mathrm{~g} / \mathrm{kg}$ per $\mathrm{d} ; P<0 \cdot 001$ ). Infants with birth weight $1000-1500 \mathrm{~g}$ had the lowest weight gain at the end of the study period $(>37$ weeks PCA: $8.9 \mathrm{~g} / \mathrm{kg}$ 
per d, $<37$ weeks PCA: $16 \cdot 4 \mathrm{~g} / \mathrm{kg}$ per d; $P<0 \cdot 001)$. We did not find any sex difference in growth, neither for the total period nor for subperiods of hospitalisation in the study.

\section{Association between nutrient intake and growth restriction at discharge}

Association between nutrient intake, anthropometric factors and growth restriction at discharge was only examined in infants of adequate weight for age at birth $(n$ 74). In the crude analyses, we found that weight ratio at birth (actual weight/50th percentile weight for gestational age at birth) and ethnicity were associated with growth restriction at discharge (Table 2). We did not observe any significant association between growth restriction and gestational age at birth, duration of respiratory support or sex. Mutual adjustment for all variables did not change these findings (Table 2).

We observed reduced odds of becoming growth restricted with increasing energy intake during the study period: crude $\mathrm{OR}=0.28$ for the second tertile and 0.11 for the upper tertile of the energy intake $\left(P_{\text {trend }}=0.001\right)$ (Table 2$)$. The OR were only slightly changed after adjustment for

Table 1. Characteristics of mothers and infants

(Mean values and standard deviations)

\begin{tabular}{|c|c|c|c|c|c|c|c|}
\hline & \multicolumn{2}{|c|}{ All $(n 127)$} & \multicolumn{2}{|c|}{$\begin{array}{l}\text { Growth restricted at } \\
\text { discharge }(n 72)\end{array}$} & \multicolumn{2}{|c|}{$\begin{array}{l}\text { Adequate weight at } \\
\text { discharge }(n 55)\end{array}$} & \multirow[b]{2}{*}{$P$} \\
\hline & Mean & SD & Mean & SD & Mean & SD & \\
\hline \multicolumn{8}{|l|}{ Maternal characteristics } \\
\hline Age (years) & 31 & 5 & 31 & 5 & 31 & 5 & 0.62 \\
\hline Non-smokers (\%) & \multicolumn{2}{|c|}{78} & \multicolumn{2}{|c|}{82} & \multicolumn{2}{|c|}{72} & 0.21 \\
\hline \multicolumn{8}{|l|}{ Infant characteristics } \\
\hline SGA at birth (\%) & \multicolumn{2}{|c|}{33} & \multicolumn{2}{|c|}{63} & \multicolumn{2}{|c|}{11} & $<0.001$ \\
\hline Boys $(\%)$ & \multirow{2}{*}{\multicolumn{2}{|c|}{55}} & \multicolumn{2}{|c|}{37} & \multicolumn{2}{|c|}{55} & 0.13 \\
\hline Non-Caucasian (\%) & & & \multicolumn{2}{|c|}{26} & \multicolumn{2}{|c|}{11} & 0.04 \\
\hline Age at discharge (weeks) & 38.9 & 4 & $39 \cdot 0$ & 4 & $38 \cdot 8$ & 3 & 0.72 \\
\hline Hospitalisation (d) & 71 & 34 & 66 & 37 & 77 & 28 & 0.06 \\
\hline \multicolumn{8}{|l|}{ Respiratory support (d) } \\
\hline Median & \multirow{2}{*}{\multicolumn{2}{|c|}{$\begin{array}{c}24 \\
3-47\end{array}$}} & \multicolumn{2}{|c|}{11} & & & 0.03 \\
\hline Interquartile range & & & & & & & \\
\hline Steroid treatment $(\%)$ & & & & & & & 0.44 \\
\hline Caesarian section (\%) & & & & & & & 0.08 \\
\hline Anthropometry & & & & & & & \\
\hline Birth weight $(\mathrm{g})$ & 1066 & 285 & 1055 & 296 & 1082 & 271 & 0.59 \\
\hline Initial weight loss (g) & 169 & 200 & 233 & 184 & 110 & 175 & 0.73 \\
\hline Time to regain birth weight (d) & 9.8 & 4 & $10 \cdot 2$ & 4 & 9.5 & 4 & 0.37 \\
\hline Gestational age at birth (weeks) & $28 \cdot 8$ & $2 \cdot 7$ & $29 \cdot 6$ & 3 & $27 \cdot 8$ & 2 & $<0.001$ \\
\hline Length at birth $(\mathrm{cm})^{*}$ & $35 \cdot 3$ & $4 \cdot 2$ & 34.9 & 4.5 & $35 \cdot 9$ & 3.5 & 0.29 \\
\hline Head circumference at birth $(\mathrm{cm})$ & $26 \cdot 5$ & 2.5 & 26.5 & $2 \cdot 8$ & 26.4 & $2 \cdot 2$ & 0.78 \\
\hline Weight at discharge $(\mathrm{g})$ & 2683 & 656 & 2417 & 601 & 3055 & 541 & $<0.001$ \\
\hline Length at discharge $(\mathrm{cm})^{\star}$ & $44 \cdot 6$ & 4.6 & $44 \cdot 1$ & 4.8 & 45.5 & 4.4 & 0.19 \\
\hline Head circumference at discharge $(\mathrm{cm})$ & 34.4 & $2 \cdot 6$ & $34 \cdot 0$ & $2 \cdot 7$ & 34.9 & $2 \cdot 4$ & $0 \cdot 10$ \\
\hline Weight gain $(g / d)$ & $23 \cdot 3$ & 5 & $21 \cdot 2$ & 4 & $26 \cdot 1$ & 5 & $<0.001$ \\
\hline$<28$ weeks & $16 \cdot 3$ & 8 & $16 \cdot 3$ & 9 & $16 \cdot 4$ & 7 & 0.92 \\
\hline $29-32$ weeks & $29 \cdot 1$ & 8 & $24 \cdot 8$ & 6 & 33.3 & 8 & $<0.001$ \\
\hline $33-36$ weeks & $29 \cdot 3$ & 5 & $28 \cdot 7$ & 5 & $29 \cdot 8$ & 6 & 0.54 \\
\hline$>37$ weeks & $27 \cdot 0$ & 7 & $26 \cdot 1$ & 8 & $27 \cdot 8$ & 7 & 0.71 \\
\hline Nutrition & & & & & & & \\
\hline Age at full enteral feed (d) & & & & & & & \\
\hline Median & & & & & & & 0.65 \\
\hline Interquartile range & & & & & & & \\
\hline Energy $(\mathrm{kJ} / \mathrm{d})$ & 787 & 121 & 749 & 117 & 853 & 92 & $<0.001$ \\
\hline Energy $(\mathrm{kJ} / \mathrm{kg}$ per $\mathrm{d})$ & 506 & 52 & 505 & 59 & 507 & 42 & 0.79 \\
\hline Recommended energy intake (\%)‡ & & & & & & & \\
\hline$<28$ weeks & & & & & & & 0.29 \\
\hline $29-32$ weeks & & & & & & & $<0.001$ \\
\hline $33-36$ weeks & & & & & & & 0.08 \\
\hline$>37$ weeks $\dagger$ & & & & & & & 0.26 \\
\hline Protein $(\mathrm{g} / \mathrm{d})$ & $5 \cdot 3$ & 0.9 & $5 \cdot 0$ & 1.0 & $5 \cdot 7$ & 0.7 & $<0.001$ \\
\hline Protein ( $\mathrm{g} / \mathrm{d}$ per $\mathrm{kg}$ ) & $3 \cdot 1$ & 0.4 & $3 \cdot 1$ & 0.4 & $3 \cdot 1$ & 0.4 & 0.38 \\
\hline Fat $(g / d)$ & 805 & 112 & $10 \cdot 0$ & $2 \cdot 1$ & 11.4 & 1.5 & 0.03 \\
\hline Vitamin A $(\mu \mathrm{g} / \mathrm{d})$ & 51 & 8 & 791 & 105 & 825 & 119 & 0.09 \\
\hline Vitamin D $(\mu \mathrm{g} / \mathrm{d})$ & $10 \cdot 7$ & 1.7 & $10 \cdot 4$ & 1.6 & $11 \cdot 0$ & 1.9 & 0.08 \\
\hline $\mathrm{Ca}(\mathrm{mg} / \mathrm{d})$ & 183 & 65 & 174 & 70 & 195 & 55 & 0.06 \\
\hline
\end{tabular}

SGA, small for gestational age.

* Length was measured in seventy-six infants at birth and in seventy-eight at discharge, due to different routines at the hospitals. †Fourteen infants in the growth-restricted group and eighteen infants with adequate growth were discharged before 37 weeks.

$\ddagger$ Infants receiving recommended energy intake: $>500 \mathrm{~kJ} / \mathrm{kg}$ per d. 

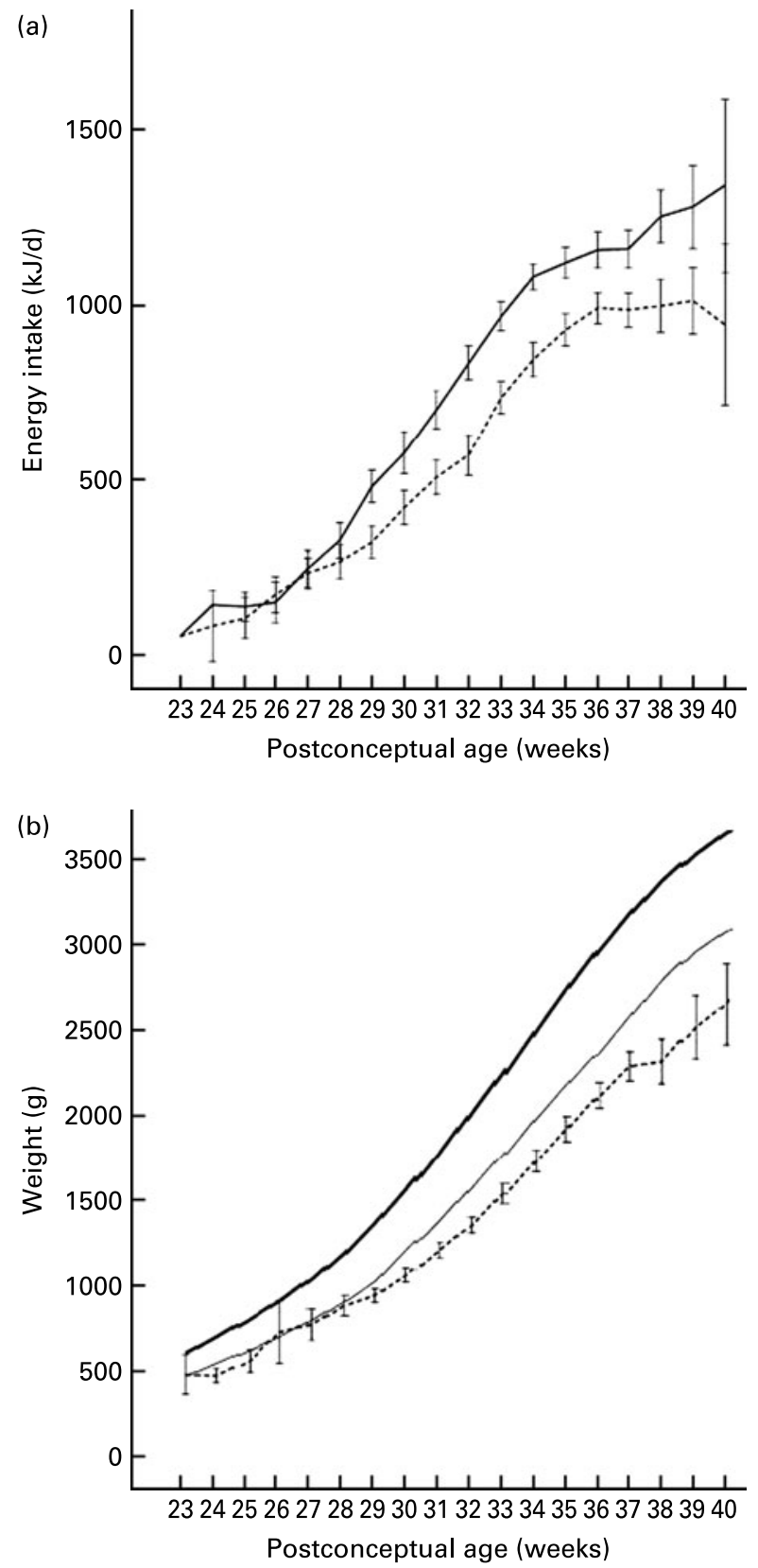

Fig. 1. (a) Intake of energy among growth-restricted infants at discharge $(n 74 ;---)$ and infants with adequate weight at discharge $(n 53 ;-)$. Values are means, with standard deviations represented by vertical bars. There was a significant interaction between post-conceptional age and growth status at discharge $(P<0.001)$. (b) Body weight among study infants $(n 127 ;--)$ compared with the reference intra-uterine growth chart $(-$, mean;,- 10 th percentile) for Norwegian infants ${ }^{(13)}$. For the study infants, values are means, with $95 \% \mathrm{Cl}$ represented by vertical bars.

birth weight ratio and ethnicity (Table 2). Additional adjustment for gestational age (weeks), respiratory support (d), length of hospitalisation (d) and sex did not change the results (data not shown).

There were significant associations between growth restriction and intake of protein, fat and $\mathrm{Ca}$. However, after adjustment for energy intake, we did not find any protective effect of single nutrients (Table 2) although we noticed a positive trend for energy-adjusted fat intake $(P=0.06)$.

\section{Discussion}

The present study shows that extra-uterine growth restriction is common in VLBW infants fed fortified human milk. Furthermore, we found an association between high energy intake and risk for growth restriction at discharge. The proportion of growth-restricted infants at discharge was $58 \%$ in the present study, which is lower than the $89-97 \%$ reported by others using formula ${ }^{(11,16,17)}$. In the present study, human milk was used from the first day of life and throughout the whole observation period. This may provide several advantages such as better and faster tolerance for enteral feeding and fewer infections, contributing to improved growth ${ }^{(5,6)}$. Moreover, the infants in the present study were born $>5-10$ years later than those reported in the previous studies and may thus have benefited from general improvements in medical care and treatment. Clark et al. ${ }^{(18)}$ reported a lower incidence of growth-restricted infants at discharge (28\%), but the mean birth weight of their infants was high compared with the infants in the present study $(1 \cdot 7 v .1 \cdot 1 \mathrm{~kg})$. Different infant growth standards were used in these studies, which also must be taken into consideration. The Norwegian growth chart has slightly higher weights compared with the international growth chart ${ }^{(19)}$, but the difference is small. When calculations are done with Babson \& Benda's growth chart, the proportion of growth-restricted infants at discharge was $55 \%$ in the present study.

The major strength of the present study is the very detailed information on nutrient intake calculated on the basis of medical records. Moreover, the participants were consecutively included from four different neonatal units, which justifies the assumption that they are representative of the population of VLBW infants in Norway. An advantage with a weight- rather than length-based endpoint was that weight is more accurately measured than length, especially in very small infants. However, adequate weight for age is not necessarily equivalent to adequate growth. Increased weight gain may reflect increased adiposity rather than symmetric weight and length growth. Ideally, measurement of body composition should be included in these types of studies.

The currently recommended energy intake is $440-540 \mathrm{~kJ} / \mathrm{kg}$ per $\mathrm{d}$ for growing preterm infants, and $500 \mathrm{~kJ} / \mathrm{kg}$ per $\mathrm{d}$ is often used as a goal ${ }^{(10)}$. In the present study, the energy intake fell short of this, most markedly in the beginning and at the end of the study period. The low intake during the first weeks was expected, and in accordance with earlier reports ${ }^{(20,21)}$. The low energy intake during the end of the hospital stay was associated with low growth rate. This was somewhat surprising, and has to our knowledge not been described earlier. We speculate that this may be due to the high frequency of breast-feeding reported for the Norwegian population, and thereby cessation of the energy and protein fortification of the human milk. Especially the infants with few medical complications and higher gestational age were introduced to early breast-feeding and cessation of fortification at an early stage. Most of these infants also had a shorter hospital stay than infants with low gestational age and medical complications. This might be one reason why infants with higher gestational age and short hospital stay received lower energy supply and had a more pronounced decline in growth towards the end of the hospital stay. Infants with medical complications 
Table 2. Associations between clinical variables, dietary intake and growth restriction (body weight $<10$ th percentile) among infants with adequate weight for gestational age at birth ( $n 74)$

(Odds ratios and $95 \%$ confidence intervals)

\begin{tabular}{|c|c|c|c|c|c|}
\hline Variable & Infants $(n)^{\star}$ & Crude OR & $95 \% \mathrm{Cl}$ & Adjusted OR† & $95 \% \mathrm{Cl}$ \\
\hline \multicolumn{6}{|c|}{ Gestational age at birth (weeks) } \\
\hline$<27$ & & 1.00 & & 1.00 & \\
\hline 28 & & 1.52 & $0.47,4.95$ & 3.59 & $0.54,23.89$ \\
\hline$>29$ & & 1.74 & $0.52,5.74$ & 3.53 & $0.37,37.40$ \\
\hline$P_{\text {trend }}$ & & 0.37 & & $0 \cdot 26$ & \\
\hline \multicolumn{6}{|l|}{ Weight ratio at birth } \\
\hline$<0.89$ & & 1.00 & & 1.00 & \\
\hline $0.90-1.00$ & & 0.08 & $0.02,0.31$ & 0.06 & $0.01,0.31$ \\
\hline$>1.01$ & & $0 \cdot 13$ & $0.04,0.46$ & 0.11 & $0.02,0.49$ \\
\hline$P_{\text {trend }}$ & & 0.001 & & 0.004 & \\
\hline \multicolumn{6}{|c|}{ Respiratory support (d) } \\
\hline$<19$ & & 1.00 & & 1.00 & \\
\hline $20-42$ & & 1.33 & $0.42,4 \cdot 28$ & 1.48 & $0.31,7.09$ \\
\hline$>43$ & & $1 \cdot 13$ & $0.35,3.65$ & $3 \cdot 40$ & $0.40,28.56$ \\
\hline$P_{\text {trend }}$ & & 0.85 & & 0.37 & \\
\hline \multicolumn{6}{|l|}{ Ethnicity } \\
\hline Caucasian & & 1.00 & & 1.00 & \\
\hline Non-Caucasian & & 3.42 & $1.06,11.03$ & 4.91 & $1 \cdot 13,21 \cdot 31$ \\
\hline$P$ & & 0.04 & & 0.03 & \\
\hline \multicolumn{6}{|l|}{ Sex } \\
\hline Girl & & 1.00 & & 1.00 & \\
\hline Boy & & 0.48 & $0 \cdot 18,1 \cdot 25$ & 0.41 & $0.12,1.46$ \\
\hline$P$ & & 0.13 & & 0.21 & \\
\hline \multicolumn{6}{|l|}{ Energy (kJ) } \\
\hline$<772$ & $15 / 9$ & 1.00 & & 1.00 & \\
\hline $773-881$ & $8 / 17$ & 0.28 & $0.09,0.92$ & 0.25 & $0.05,1.25$ \\
\hline$>882$ & $4 / 21$ & $0 \cdot 11$ & $0.03,0.44$ & 0.06 & $0.01,0.34$ \\
\hline \multirow{2}{*}{\multicolumn{6}{|c|}{ Protein (g) }} \\
\hline & & & & & \\
\hline$<5.1$ & $14 / 10$ & 1.00 & & 1.00 & \\
\hline $5 \cdot 2-5 \cdot 9$ & $8 / 17$ & 0.34 & $0.11,1.08$ & 0.54 & $0.09,3.18$ \\
\hline$>6 \cdot 0$ & $5 / 20$ & $0 \cdot 18$ & $0.05,0.64$ & $3 \cdot 14$ & $0.60,16 \cdot 42$ \\
\hline$P_{\text {trend }}$ & & 0.007 & & $0 \cdot 16$ & \\
\hline \multicolumn{6}{|l|}{ Fat $(\mathrm{g})$} \\
\hline$<10.00$ & $15 / 9$ & 1.00 & & 1.00 & \\
\hline $10 \cdot 01-11 \cdot 73$ & $7 / 18$ & 0.23 & $0.07,0.78$ & $2 \cdot 39$ & $0.33,17.29$ \\
\hline$>11.74$ & $5 / 20$ & 0.15 & $0.04,0.54$ & $6 \cdot 38$ & $0 \cdot 87,46 \cdot 81$ \\
\hline \multicolumn{6}{|l|}{$\mathrm{Ca}(\mathrm{mg})$} \\
\hline$<156$ & $15 / 9$ & 1.00 & & 1.00 & \\
\hline $157-178$ & $6 / 19$ & $0 \cdot 19$ & $0.06,0.65$ & 0.57 & $0.08,4.25$ \\
\hline$>179$ & $6 / 19$ & 0.19 & $0.06,0.65$ & 1.33 & $0.22,8 \cdot 23$ \\
\hline$P_{\text {trend }}$ & & 0.007 & & 0.59 & \\
\hline \multicolumn{6}{|l|}{ Vitamin A $(\mu \mathrm{g})$} \\
\hline$<779$ & 9/15 & 1.00 & & 1.00 & \\
\hline $780-835$ & $6 / 19$ & 0.53 & $0 \cdot 15,1 \cdot 81$ & 0.67 & $0.15,2.95$ \\
\hline$>836$ & $12 / 13$ & 1.54 & $0.49,4.81$ & 1.65 & $0 \cdot 40,6 \cdot 81$ \\
\hline$P_{\text {trend }}$ & & 0.44 & & 0.48 & \\
\hline \multicolumn{6}{|l|}{ Vitamin D $(\mu \mathrm{g})$} \\
\hline$<10.4$ & 9/15 & 1.00 & & 1.00 & \\
\hline $10 \cdot 5-11 \cdot 4$ & $8 / 17$ & 0.78 & $0.24,2.55$ & 0.76 & $0 \cdot 18,3 \cdot 21$ \\
\hline$>11.5$ & $10 / 15$ & $1 \cdot 11$ & $0.35,3.51$ & $2 \cdot 34$ & $0.52,10.65$ \\
\hline$P_{\text {trend }}$ & & 0.85 & & 0.30 & \\
\hline
\end{tabular}

*Growth restriction/adequate growth.

†Adjusted for weight ratio at birth and ethnicity. Protein, fat and Ca are also energy adjusted by the residual method, and energy is included in the models for these variables.

were on the contrary kept in hospital for a longer time period and thereby received parenteral nutrition and fortified human milk longer to cover their nutrient needs. It is not known if the positive effect of exclusive early breast-feeding outweighs the negative effect of growth failure at this age, as opposed to continuation of feeding with fortified human milk.

Postnatal growth failure is due to a complex interaction of genetic and environmental factors, including inadequate nutrition, morbidity affecting nutrient requirements and metabolism, endocrine abnormalities and treatments ${ }^{(22)}$. After adjustment for possible confounders, only low energy intake, birth weight ratio and ethnicity were independently associated with growth restriction. Berry et al. ${ }^{(23)}$ found that growth failure may be related to the use of dexamethasone and duration of respiratory support to ELBW infants, and that low energy intake was regarded as a consequence of the medical condition. Among infants with adequate weight at birth, we did not find any association between respiratory support, use of dexamethasone and growth failure. 
We did not observe any significant association between growth restriction and intake of protein or $\mathrm{Ca}$ after adjusting for energy, probably because energy supply and nutrient supply were strongly correlated. We noticed a positive trend between growth restriction and fat intake (energy adjusted), but the OR were not significant.

Although the boys had a slightly higher energy intake compared with the girls in the small-for-gestational-age group, we were not able to detect any sex difference in energy and protein intake per kg body weight, or in growth. This may be due to low statistical power.

Growth restriction in VLBW infants may lead to altered brain function, promoting impaired long-term neurodevelopment and reduced intelligence quotient ${ }^{(24,25)}$. These observations are supported by several animal studies, for example, showing decreased hippocampal size in undernourished rat pups ${ }^{(26)}$.

In humans it has been shown that catch-up growth is beneficial because it is associated with higher head circumference and higher intelligence quotient in adulthood ${ }^{(27)}$. On the other hand, catch-up growth may also represent a risk factor for the development of CHD and the metabolic syndrome later in life. This is probably due to altered programming of endothelial function, as well as changes in the expression of important growth factor receptor binding ligands such as insulin and leptin $^{(28-31)}$. In preterm infants, the potential beneficial effect of catch-up growth on the central nervous system may outweigh the increased risk of cardiovascular heart disease, thus adequate growth should be prioritised ${ }^{(29)}$. The optimal solution would be to characterise individual energy supply to ensure proper growth of the central nervous system without excessive accumulation of adipose tissue.

\section{Conclusion}

Extra-uterine growth restriction is common in VLBW infants fed fortified human milk. Recommended energy intakes for growing preterm infants were not met in the present study. We observed a significant positive association between energy intake and reduced risk of growth restriction at discharge. The present study shows that preterm infants have low weight gain in the beginning and at the end of the hospital stay. The smallest ELBW infants, who have high co-morbidity and require a long period on parenteral nutrition, have the lowest weight gain in the first month of life. The relatively large preterm infants, characterised by early full enteral feeding and initiation of breast-feeding without fortification, have the lowest weight gain in the last period before discharge. From the design of the present study, we cannot definitely conclude that the observed association between energy intake and growth restriction reflects a casual effect, and further studies are needed to examine this question. Further studies are also needed to evaluate the safety and efficacy of increased energy and nutrient intake to obtain adequate growth, with minimal adverse effects, in preterm infants.

\section{Acknowledgements}

C. H., C. A. D. and P. O. I. designed the study and were responsible for the data analyses and writing of the manuscript. C. H. was responsible for the data collection and wrote the first draft of the manuscript. A. C. W., A. R. and B. N. participated in the collection and analysis of data and contributed to the writing of the manuscript. M. B. V. was responsible for the statistical analyses and contributed to the writing of the manuscript.

We thank the medical and nursing staff at Akershus University Hospital, Buskerud Hospital, Rikshospitalet University Hospital and Vestfold Hospital for excellent collaboration.

Financial support for the present study was obtained from the Norwegian Foundation for Health and Rehabilitation, the Johan Throne Holst Foundation for Nutrition Research, Freia Medical Research Foundation, the Research Council of Norway and Thematic Program on Perinatal Nutrition, Faculty of Medicine, University of Oslo.

The funding does not pose any conflicts of interest to the study.

\section{References}

1. Dewey K \& Lutter C (2006) Guiding Priniciples for Complementary Feeding of the Breastfed Child. Washington, DC: WHO Division of Health Promotion and Protection. Food and Nutrition Program.

2. Parish A \& Bhatia J (2008) Early aggressive nutrition for the premature infant. Neonatology 94, 211-214.

3. National Board of Health (2002), Best Practice on Milkbanks in Norway, IK-2760. Oslo: National Board of Health.

4. Lucas A, Morley R, Cole TJ, et al. (1992) Breast milk and subsequent intelligence quotient in children born preterm. Lancet 339, 261-264.

5. Ronnestad A, Abrahamsen TG, Medbo S, et al. (2005) Lateonset septicemia in a Norwegian national cohort of extremely premature infants receiving very early full human milk feeding. Pediatrics 115, e269-e276.

6. Heiman H \& Schanler RJ (2006) Benefits of maternal and donor human milk for premature infants. Early Hum Dev 82, 781-787.

7. O'Connor DL, Jacobs J, Hall R, et al. (2003) Growth and development of premature infants fed predominantly human milk, predominantly premature infant formula, or a combination of human milk and premature formula. J Pediatr Gastroenterol Nutr 37, 437-446.

8. Kuschel CA \& Harding JE (2004) Multicomponent fortified human milk for promoting growth in preterm infants. The Cochrane Database of Systematic Reviews 2004, issue 1, CD000343. http://www.mrw.interscience.wiley.com/cochrane/ clsysrev/articles/CD000343/frame.html

9. Rotteveel J, van Weissenbruch MM, Twisk JW, et al. (2008) Infant and childhood growth patterns, insulin sensitivity, and blood pressure in prematurely born young adults. Pediatrics 122, 313-321.

10. American Academy of Pediatrics (1998) Pediatric Nutrition Handbook, 4th ed. [RE Kleinman, editor]. Elk Grove Village, IL: American Academy of Pediatrics.

11. Fewtrell MS (2003) Growth and nutrition after discharge. Semin Neonatol 8, 169-176.

12. Henriksen C, Haugholt K, Lindgren M, et al. (2008) Improved cognitive development among preterm infants attributable to early supplementation of human milk with docosahexaenoic acid and arachidonic acid. Pediatrics 121, 1137-1145.

13. Skjaerven R, Gjessing HK \& Bakketeig LS (2000) Birthweight by gestational age in Norway. Acta Obstet Gynecol Scand 79, $440-449$.

14. Saarela T, Kokkonen J \& Koivisto M (2005) Macronutrient and energy contents of human milk fractions during the first six months of lactation. Acta Paediatr 94, 1176-1181. 
15. Willett W (1998) Nutritional Epidemiology, 2nd ed. New York: Oxford University Press.

16. Ehrenkranz RA, Younes N, Lemons JA, et al. (1999) Longitudinal growth of hospitalized very low birth weight infants. Pediatrics 104, 280-289.

17. Lemons JA, Bauer CR, Oh W, et al. (2001) Very low birth weight outcomes of the National Institute of Child Health and Human Development Neonatal Research Network, January 1995 through December 1996. NICHD Neonatal Research Network. Pediatrics 107, E1.

18. Clark RH, Thomas P \& Peabody J (2003) Extrauterine growth restriction remains a serious problem in prematurely born neonates. Pediatrics 111, 986-990.

19. Fenton TR (2003) A new growth chart for preterm babies: Babson and Benda's chart updated with recent data and a new format. BMC Pediatr 3, 13.

20. Menon G, Boyle EM, Embleton ND, et al. (2004) Introduction of enteral feeds in preterm infants. Pediatrics 114, 327-328.

21. Embleton NE, Pang N \& Cooke RJ (2001) Postnatal malnutrition and growth retardation: an inevitable consequence of current recommendations in preterm infants? Pediatrics 107, $270-273$.

22. De CM \& Rigo J (2004) Extrauterine growth restriction in very-low-birthweight infants. Acta Paediatr 93, 1563-1568.

23. Berry MA, Abrahamowicz M \& Usher RH (1997) Factors associated with growth of extremely premature infants during initial hospitalization. Pediatrics 100, 640-646.
24. Lucas A, Morley R \& Cole TJ (1998) Randomised trial of early diet in preterm babies and later intelligence quotient. BMJ 317, $1481-1487$.

25. Black LS, deRegnier RA, Long J, et al. (2004) Electrographic imaging of recognition memory in 34-38 week gestation intrauterine growth restricted newborns. Exp Neurol 190, Suppl. 1, $\mathrm{S} 72-\mathrm{S} 83$.

26. Mallard C, Loeliger M, Copolov D, et al. (2000) Reduced number of neurons in the hippocampus and the cerebellum in the postnatal guinea-pig following intrauterine growth-restriction. Neuroscience 100, 327-333.

27. Brandt I, Sticker EJ \& Lentze MJ (2003) Catch-up growth of head circumference of very low birth weight, small for gestational age preterm infants and mental development to adulthood. J Pediatr 142, 463-468.

28. Barker DJ, Winter PD, Osmond C, et al. (1989) Weight in infancy and death from ischaemic heart disease. Lancet ii, 577-580.

29. Singhal A, Cole TJ, Fewtrell M, et al. (2004) Is slower early growth beneficial for long-term cardiovascular health? Circulation 109, 1108-1113.

30. Singhal A, Farooqi IS, O'Rahilly S, et al. (2002) Early nutrition and leptin concentrations in later life. Am J Clin Nutr 75, 993-999.

31. Singhal A, Fewtrell M, Cole TJ, et al. (2003) Low nutrient intake and early growth for later insulin resistance in adolescents born preterm. Lancet 361, 1089-1097. 